\title{
Study of Comorbidity in Mentally Retarded Children
}

\author{
Rakesh Gandhi ${ }^{1}$, Mahesh Kumar Suthar ${ }^{2}$, Animesh Patel ${ }^{3}$ \\ ${ }^{1}$ Associate Professor, ${ }^{2}$ Assistant Professor, ${ }^{3}$ Resident, \\ Department of Psychiatry, Medical College Baroda,Vadodara, Gujrat, India.
}

\begin{abstract}
Introduction: Mental retardation is the most disabling among all disabilities with significant consequences for the individual themselves, their families and the society. Co-morbidities in mental Retardation are important for service and treatment planning.

Aims: Objective of study to find out prevalence of psychiatric and medical co-morbidities in mentally retarded children and compare occurrence of co-morbidity with degree of mental retardation.

Materials and Methods: 100 Patients taken from the outdoor psychiatric department of tertiary care hospital, Co-morbidities assessed by clinical interview, psychological testing ,physical examination and old records of subjects and parents.

Results: Among study population $72 \%$ subjects found with comorbidity, $54 \%$ had psychiatric co-morbidity, $36 \%$ were having medical co-morbidity and 10\% were having both. Higher prevalence of psychiatric co-morbidity was found among mild and moderate mentally retarded subjects while medical comorbidity was found to be greater in subjects of severe and profound mental retardation.
\end{abstract}

Conclusion: Significant number of subjects with mental

\section{INTRODUCTION}

Intelligence, which is highly evolved in human beings, defined by Wechsler as the global capacity of the person and to deal effectively with his / her environment.

Mental Retardation is the most disabling of all disabilities with significant consequences for the individual themselves, their families and the society. It is often regarded as a devastating and very stigmatizing disability. The societal responses to MR may make problems complicated for these individuals. History is replete with instances of their neglect, abuse, and victimization.

Mental retardation is a condition of arrested or incomplete development of the mind, which is especially characterized by impairment of skills manifested during the developmental period, which contribute to the overall level of intelligence, i.e. cognitive, language, motor, and social abilities. (ICD-10). ${ }^{1}$

Term mental retardation carries significant social and emotional stigma. The American Association for Intellectual and Developmental Disability (AAIDD) has been particularly influential in terminology changes as intellectual disability. ${ }^{2}$

Much debate and research has centered on the prevention of MR, deinstitutionalization, and the education and employment of individuals with MR. Although mental retardation is not considered a mental illness in DSM, with its own unique signs and symptoms. It is a system of identifying groups of people who need social support and special educational services to carry out tasks of everyday living. ${ }^{3}$ retardation has psychiatric and medical co-morbidities. It is important to sensitize psychiatrists, non-psychiatric physicians and all service providers in area of intellectual disability about these co-morbidities to improve health of beneficiaries.

Keywords: Intellectual disability (I.D.), Co-morbidity, Development.

*Correspondence to:

Dr. Mahesh Kumar Suthar, 12/ C Gurukrupa society, Opposite Shayog, Refinery Road, Gorwa, Vadodara.Gujarat.

Email: drmaheshsuthar@gmail.com

Article History:

Received: 21-04-2016, Revised: 01-05-2016, Accepted: 22-05-2016

\begin{tabular}{|l|c|}
\hline \multicolumn{2}{|c|}{ Access this article online } \\
\hline $\begin{array}{l}\text { Website: } \\
\text { www.jmm.com }\end{array}$ & Quick Response code \\
\hline DOI: & \\
10.21276/jmrp.2016.2.3.055 & \\
\hline
\end{tabular}

Negative self-image, low self-esteem, poor frustration tolerance, interpersonal dependence, and a rigid problem-solving style are reflection of personality style of mentally retarded people. ${ }^{4}$

\section{MATERIAL AND METHODOLOGY}

This study is conducted with aims of to study the prevalence of severity of MR in study population, to assess the prevalence and pattern of psychiatric and medical co-morbidity in mentally retarded children and to compare occurrence of co-morbidity with degree of mental retardation. The study sample was taken from the Outdoor Psychiatric Department and consisted of 100 subjects up to age of 12 years having mental retardation as per DSM-IVTR criteria. Study material includes clinical interview of subjects and parents and consent form. The interview details consisted of demographic data, assessment of the severity of Mental Retardation and assessment of comorbidity as per DSM-IV-TR criteria. Severity of Mental Retardation was assessed with help of Clinical Psychologist by determining the IQ level and adaptive functioning capacity of the child by using standardized tests. Comorbidity with mental retardation was assessed by clinical interview as per DSM-IV-TR criteria. Clinical interview includes information regarding history of present complaints, past history, family history, and personal history with details of birth and developmental history \& physical and psychiatric examination findings with diagnostic conclusion. 


\section{RESULTS}

Among the 100 subjects with mental retardation included in the study, 47 were having mild mental retardation, 31 were having moderate mental retardation, 18 were having severe mental retardation and 4 were having profound mental retardation. (Fig 1) As shown in figure out of 100 subjects 39 were found to have psychiatric co morbidity, 26 were having medical co morbidity and 7 were having both medical and psychiatric co morbidity. 28 of all subjects were found having no any comorbidity. (Table 1)

Study of Co-morbidity in different age group shows that 24 subjects who belonged to under 6 yrs age group among them 20 patients were having comorbidity of which $10(50 \%)$ patients were found having psychiatric comorbidity and $12(60 \%)$ patients were found having medical comorbidity.

Among 76 patients who belonged to $6-12$ yrs age group, 52 patients were having comorbidity of which $36(69.23 \%)$ were found having psychiatric comorbidity and 21 (40.38\%) patients were found having medical comorbidity.

Table 2 explains pattern of various co morbidities based on severity of mental retardation. It shows that as severity of retardation increase medical co morbidities increase and mild to moderate retardation shows more psychiatric co morbidities. (Table 2)

Table 1: Distribution of Various Comorbidity in study subject

\begin{tabular}{lc}
\hline Co-morbidity & $\mathrm{N}, \%$ \\
\hline Psychiatric & 39 \\
Medical & 26 \\
Both & 07 \\
None & 28 \\
\hline
\end{tabular}

Table 2: Correlation of Degree of MR \& Co-morbidity

\begin{tabular}{lccccc}
\hline Degree of MR & $\begin{array}{c}\text { Psychiatry } \\
\text { Comorbidity (\%) }\end{array}$ & $\begin{array}{c}\text { Medical Comorbidity } \\
(\%)\end{array}$ & $\begin{array}{c}\text { Both } \\
\text { Co morbidities (\%) }\end{array}$ & None (\%) & Total \\
\hline Mild & $19(40.4)$ & $06(12.8)$ & $02(4.3)$ & $20(42.6)$ & 47 \\
Moderate & $12(38.7)$ & $07(22.6)$ & $04(12.9)$ & $08(25.8)$ & 31 \\
Severe & $07(38.9)$ & $10(55.6)$ & $01(5.6)$ & $00(0)$ & 18 \\
Profound & $01(25)$ & $03(75)$ & $00(0)$ & $00(0)$ & 04 \\
Total & 39 & 24 & 09 & 28 & 100 \\
\hline
\end{tabular}

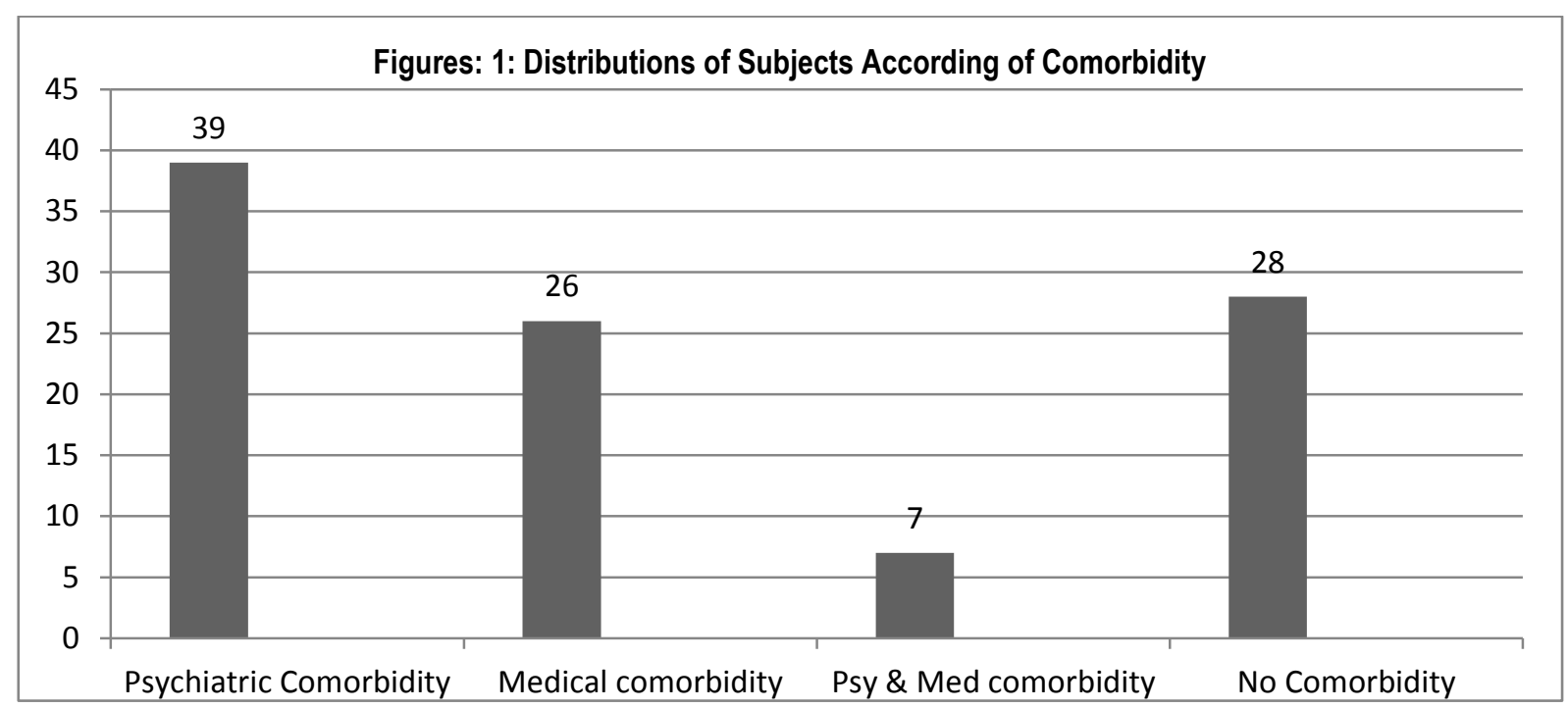

Table 3: Distribution of Psychiatric comorbidity in study subjects

\begin{tabular}{lc}
\hline Psychiatric Comorbidity & $\mathrm{N}=\mathbf{1 0 0}, \%$ \\
\hline ADHD & 11 \\
Autism & 09 \\
Learning Disability (LD) & 02 \\
Behavioral Disturbance (BD) & 12 \\
Oppositional defiant Dis. (ODD) & 02 \\
Pica & 01 \\
Enuresis & 04 \\
Tics & 01 \\
Psychotic Disorder & 03 \\
Bipolar Mood Disorder & 01 \\
Depression & 02 \\
Anxiety & 01 \\
\hline
\end{tabular}

Table 4: Distribution of Medical Co morbidity in subjects

\begin{tabular}{lc}
\hline Medical Co-morbidity & $\mathrm{N}=100, \%$ \\
\hline Epilepsy & 28 \\
CP & 04 \\
Down Syndrome & 03 \\
Hearing Impairment & 01 \\
\hline
\end{tabular}

Among psychiatric co morbidities, ADHD was found in 11 patients, autism in 9 patients, learning disorder in 2 patients, behavioral disturbance in 12 patients, opposional defiant disorder in 2 patients, pica in 1 patient, enuresis in 4 patients, tics in 1 patient, psychotic disorder in 3 patients, bipolar mood disorder in 1 patient, depression in 2 patients and anxiety in 1 patient. (Table 3)

Among medical co morbidities epilepsy was found in 28 patients, cerebral palsy in 4 patients, Down syndrome in 3 patients and hearing impairment in 1 patient. (Table 4) 


\section{DISCUSSION}

There was a higher prevalence of medical co morbidities among under 6 age groups and higher prevalence of psychiatric co morbidities among 6-12 yrs age group. This could be read as children with medical comorbidity have younger age of presentation and those with psychiatric co morbidity have later age of presentation. Medical illness might have been more easily recognized by family members as compared to psychiatric disorder. While children with psychiatric co morbidity usually have lesser degree of retardation and become manifest later in life. ${ }^{5}$

Our study we found that $39 \%$ patients were suffering from psychiatric co morbidities, $26 \%$ were having medical co morbidities while $7 \%$ were found to have both medical and psychiatric co morbidity. Overall $72 \%$ patients were found to have one or other co morbidity. This finding is consistent with most of other following studies.Prashant Jauhari, Roli Bhargava, Anupama Bhave, Chandrakanta Kumar \& Rashmi Kumar (March-2012) (Prashant Jauhari R. B., 2012) had found that $97.5 \%$ patients had one or more associated co morbidities and $58.2 \%$ had two or more co morbidities. ${ }^{6}$ Amaral, Pinto, Pimentel, Martins, and Vale (2010) found co morbidities in $66 \%$ of children with ID. ${ }^{7}$

Our study subjects with mild to moderate mental retardation had greater occurrence of psychiatric disorder compared to severe to profound MR subjects who had greater occurrence of medical co morbidity. Prashant Jauhari, Roli Bhargava, Anupama Bhave, Chandrakanta kumar \& Rashmi Kumar had conducted study on comorbidites associated with ID at a teaching hospital at northern India and found that prevalence of most of the neurological and medical problems increased with severity of ID while ADHD, autism \& behavioral problems decreased. ${ }^{6}$

Among psychiatric co morbidity, Unspecified behavioral disturbance(12\%) was the most frequent disorder followed by ADHD (11\%), autism (9\%), enuresis (4\%), and others which are comparable with oeseburg et al says high prevalence of autism in children with ID ranging from $10-20 \%{ }^{8}$, Stromme \& Diseth (2000) found hyperkinesias in 16\%; pervasive developmental disorders in $8 \%$, autism in $4.5 \%$, behavioral or emotional conditions in $6 \%$, conduct in $3 \%$, Anxiety/phobias/obsession-compulsive in $3 \%$ \& Tics in $1 \%$ of patients. ${ }^{9,10}$

Among medical co morbidity, epilepsy (28\%) was the most frequent disorder followed by cerebral palsy (4\%), Down syndrome $(3 \%)$ and hearing impairment $(1 \%)$ which are similar with Christoday et all medical conditions in $35 \%$ and commonest is epilepsy. ${ }^{11}$

\section{CONCLUSION}

Children with medical co morbidity have younger age of presentation and those with psychiatric co morbidity have later age of presentation. Younger age group patients $(0-6 \mathrm{yrs})$ those who have greater degree of mental retardation due to underlying medical illness making them seek health care services early in life. While children with psychiatric co morbidity usually have lesser degree of retardation and become manifest later in life when demand increases making them to present later in life.
Higher prevalence of psychiatric co morbidity was found among children with mild to moderate mental retardation while children with severe to profound mental retardation had greater prevalence of medical co morbidity. As the severity of mental retardation increased prevalence of medical co morbidity also increased. Epilepsy is most commonly associated. Unspecified behavioral disturbances were the most common psychiatric co morbidity found followed by ADHD and autism.

\section{REFERENCES}

1. (WHO), W. H. (1992). The ICD-10 classification of Mental \& Behavioral Disorders. Clinical description and diagnostic guidelines. Geneva

2. Schroeder S, G. M. (2002). Final Project Report: Usage of the Term "Mental Retardation:" Language, Image and Public Education. Social Security Administration.

3. Benjamin James Sadock, V. A. (2010). Synopsis of Psychiatry Behavioral Sciencs/Clinical Psychiatry (10th ed.). wolters kluwer.

4. C Simon Sebastian, M. (2011, Dec 30). Pediatric Mental Retardation. (M. F. Iqbal Ahmed, Editor) Retrieved Nov 9, 2011, from http://emedicine.medscape.com/article/289117.

5. Christoday R.J. Khess, I. D. (1998). Comorbidity In Children With Mental Retardation. Indian journal of Psychiatry , 40(3), 289-294.

6. Prashant Jauhari, R. B. (2012). Journal of Policy and Practice in Intellectual Disabilities , 9, 10-16.

7. Amaral, R. P. (2010). Mental retardation: Case series of Dona Estefânia Hospital child development centre. Acta Médica Portuguesa , 23, 993-1000.

8. Oeseburg, B. D. (2011). Prevalence of chronic health conditions in children with intellectual disability: A systematic literature review. Journal of Intellectual and Developmental Disabili , 59-85.

9. Strømme, P. \&. (2000). Prevalence of psychiatric diagnoses in children with mental retardation: Data from a population-based study. Developmental Medicine \& Child Neurology , 42, 266-270.

10. Emerson, E. (2003). Prevalence of psychiatric disorders in children and adolescents with and without intellectual disability. Journal of Intellectual Disability Research , 47 , 51-58.

11. Christoday R.J. Khess, I. D. (1998). Co Morbidty in Children With Mental Retardatioin Indian journal of Psychiatry , 40(3), 289-294.

\section{Source of Support: Nil. Conflict of Interest: None Declared.}

Copyright: (c) the author(s) and publisher. IJMRP is an official publication of Ibn Sina Academy of Medieval Medicine \& Sciences, registered in 2001 under Indian Trusts Act, 1882.

This is an open access article distributed under the terms of the Creative Commons Attribution Non-commercial License, which permits unrestricted non-commercial use, distribution, and reproduction in any medium, provided the original work is properly cited.

Cite this article as: Rakesh Gandhi, Mahesh Kumar Suthar, Animesh Patel. Study of Comorbidity in Mentally Retarded Children. Int J Med Res Prof. 2016; 2(3):249-51. 